\title{
Research on Nantong Craft Arts Resources and the Corresponding Applications on Local Higher Vocational Teaching
}

\author{
Donglian Jiang \\ Jiangsu College of Engineering and Technology, \\ Nantong ,Jiangsu 226001 China
}

\begin{abstract}
In this paper, we conduct research on Nantong craft arts resources and the corresponding applications on the local higher vocational teaching. Higher vocational design class of the students' professional foundation courses, such as building design students' basic pillars design literacy, must undertake in accord with cognitive law systematically on the basis of cultivating the students from observation of thinking to create professional ability, through the innovation of curriculum, make teachers and students can enter the process of teaching and learning in the form of natural, better support for follow-up professional course learning, in order to obtain comprehensively improve the quality and ability of the students, the education effect. Under this guideline, we combine the basic features of the Nantong craft arts resources to modify traditional education mode that is beneficial.
\end{abstract}

Keywords- Nantong, Craft Arts, Local Higher Vocational, Education, Arts Resources.

\section{Introduction}

Essentially, higher vocational college is to three groups to carry out the service work, for the majority of the students, as the market, all kinds of enterprises and institutions for the current. Effective should be the education and the vocational education market effective fusion together, through the effective integration, practical and of improving the quality of education. If we want to improve quality in the current period as will be positive mechanism innovation work. Referring to the innovation not only is the school's own system innovation, more critical refers to through a variety of measures to realize the education main body diversity, through the introduction of general innovative activities to carry out the market model and to better resources allocation by the market model [1-3].

Based on the literature review, the current drawbacks and challenges of the college education can be roughly summarized as the follows. (1) Emphasis on innovation and specification while ignore the unification of both. Class teaching reform is a kind of innovation that things could be attained only in constant innovation development. Innovation is the breakthrough of the original specification, but does not mean that follow one's inclinations. Innovators must deeply understand original specification the problems existing in the original specification and reasonable content have a sober understanding. (2) Teachers teaching emphasize student self-exploration, neglected. Taught in traditional teaching mode in the process of the negative, many young teachers tried to take inquiry, such as a more novel teaching method, the lectures as synonymous with backward teaching method and to abandon them. (3) Pay attention to teaching form ignore the deep grasp of teaching basic skills and teaching content. In all sorts of the new education idea and dazzling in the classroom teaching reform, prone to focus on young teachers teaching forms of change, that ignore the deep grasp of the teaching content. (4) Pay attention to the classroom teaching environment while ignore the classroom teaching main body. The present classroom teaching reform in the emphasis on the change of the teaching environment and the use of modern technology at the same time, the two main elements of classroom teaching of teachers and students focus on relatively far less [4]. 
As people living mode of the production will increase steadily, and the traditional folk culture is gradually fade out people's field of vision. Part of the folk arts and crafts masters of old or for other reasons, led to the subsequent unmanned for succession. In the further production and development of resources, and also lack of more forward-looking investor intervention, and grassroots basic culture administrative department of relevant personnel, funds and equipment also has serious deficiencies in the reality, as the relevant government department management function has not been fully. It can be said that any kind of folk art or art, no inheritance people this link, also lost the art of life. In the figure one, we show the sample demonstration of the Nantong craft arts [5].
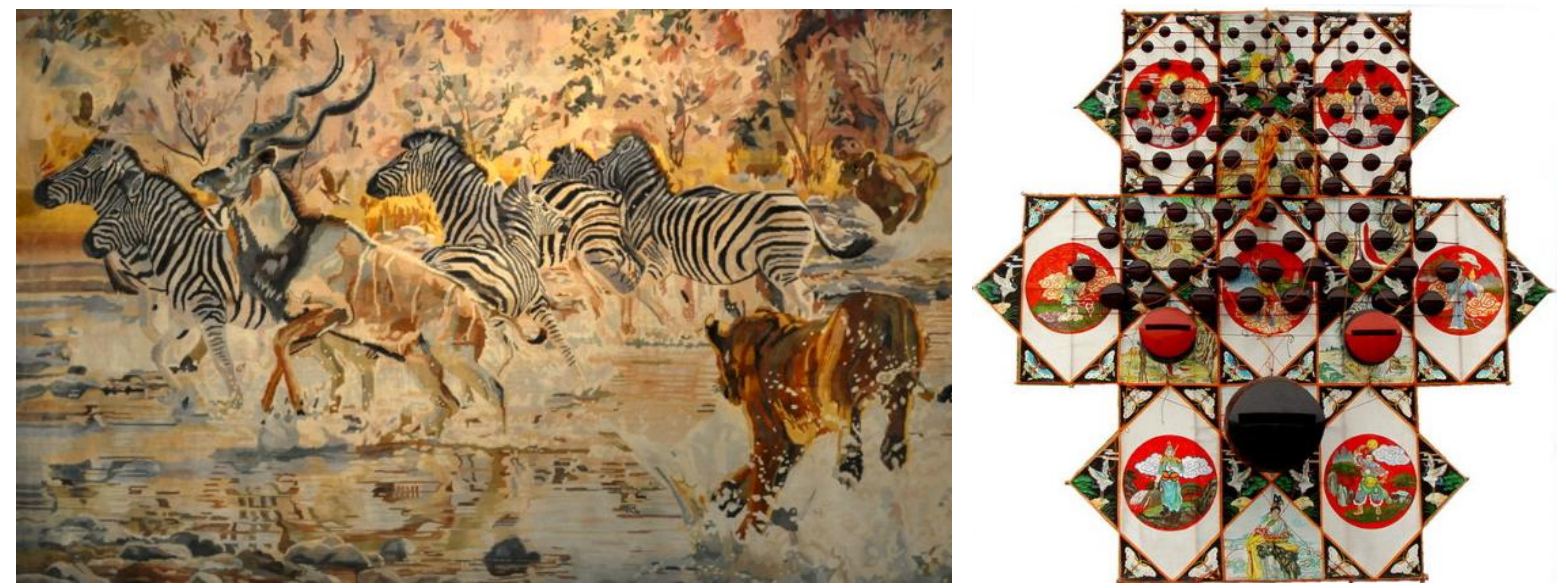

Figure 1. The Sample Demonstration of the Nantong Craft Arts

In this paper, we conduct research on Nantong craft arts resources and corresponding applications on local higher vocational teaching. Nantong culture heritage, arts and crafts a variety of resources, is the key region Jiangsu arts and crafts, repeatedly in the various arts and crafts competition awards. In this fertile soil, gave birth to a blue prints, simulation embroidery, board harrier kite, yarn-dyed cloth, rugao silk rug, carved mahogany, such as traditional folk craft, many techniques have been included in the national non-material cultural heritage list. Accelerate the development of local arts and core industry, to cultivate the unique urban industries and carry forward the national excellent traditional culture, improve the social productive forces is of great significance to speed up the pace of Nantong economic construction and development, and how to accelerate development of local arts and crafts industry based on the original is worth thinking and discussion which will be down later.

\section{The Proposed Methodology}

The Nantong Craft Arts Resources. Non-material cultural heritage vividly shows the various areas of all ethnic groups of productive labor, living custom, folk beliefs, aesthetic emotion and cognitive philosophy, and gradually formed in the process of the inheriting its own spirit. Art is the important carrier of culture, communication and record of the intangible cultural heritage content is presented in the form of art. Nantong the artistic features of the intangible cultural heritage has distinct modernity and locality, reflects the Nantong the intelligence of the people [6-7].

Groups and organizations with its environment, and the relationship of the nature and historical conditions change constantly from one generation to the intangible cultural heritage of the innovation, and make themselves have a sense of identity and history, thus promoting the cultural diversity and human creativity. The 
Chinese traditional arts and crafts for embodies the rich Chinese culture and become special commodity in the modern market economy, both economic and cultural attribute. In terms of its cultural attributes, and "culture" and "culture industry" dual role to protect and develop traditional arts and crafts in carrying the cultural connotation that is the realization of "culture" is an important part of, the government responsibility that should be actively advocates and practitioners. Development of traditional arts and crafts industry is an important aspect of bigger and the stronger cultural industry. Arts and crafts industry is a collection of art and industry as a special industry, has its special economic value. Nantong arts and crafts industry though the share of industrial economy in the city is not big, but it is a card of building China's historic city of Nantong is important. Expediting the development of arts and crafts, to carry forward the excellent traditional culture and cultivate the unique urban industries, promoting employment, increasing the income of residents, promoting the construction of city's new industrialization and economic and social development has significance.

Arts and crafts of our country in the process of history that has experienced different vicissitude of the times, in different historical and cultural background of the next generation of generation of basic inheritance up to now, there must be the charm of its own. Historically, there are a lot of technology of the production process has been passed down generation after generation, and already have their own characteristics, formed a unique culture and art. In folk art, a lot of the representative works of art has been widely circulated, and be accepted and loved. In the following figure two, we show the example of the craft arts resources in Nantong [8].

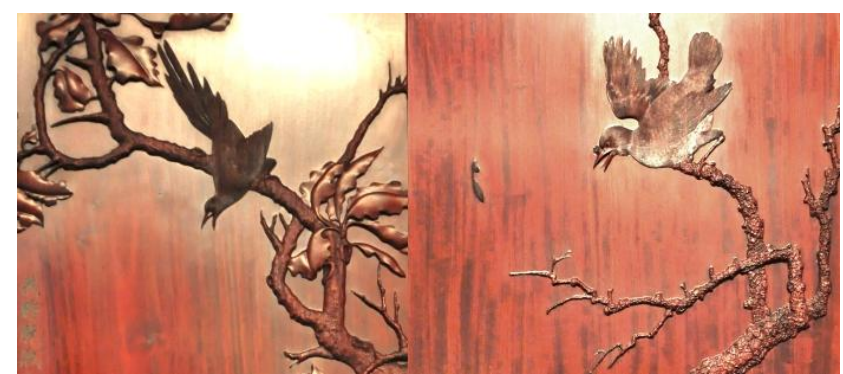

Figure 2. The Demonstrative Example of the

Craft Arts Resources in Nantong

During the transmission of arts and crafts in the long-term that has gradually become a kind of the traditional culture, in the life of people played an inestimable role, as a result of the existence of the traditional process, will make people's life more meaningful, it is the foundation of our cultural life. In the process of the development of the traditional process, people have realized that to the traditional craft in the modern have better prospects for development, must be combined with modern people's preferences and life, meet the needs of modern people. In fact, in the process of the development of modern society, the traditional process in people's life also gradually got recovery. Some traditional handicrafts as enjoyed by people and popular, because it has a simple classic beauty, with pure natural human feelings can pass the creator of the emotion with the kindness.

The Higher Vocational Teaching Reform. The traditional discipline teaching, with the teacher speaks, students listen to give priority to below above cramming education teaching mode, to take the teachers as the main body of the classroom teaching. This experiment is weak link in the teaching process, and teaching method of the single, theory with practice. Because of a lack of practice process, students' lack of themselves to experimental process and because of the traditional teaching concept and experimental conditions, many of the modern teaching methods in the teaching process without application. The talent cultivating target in higher vocational colleges is a senior applied talents, the higher requirements to the students' practical ability, is reflected in the teaching experiment 
and the training classes than theory classes. But, speaking ability training is need to experiment and training venues, places size and the equipment is perfect or not will affect the students' skill training, may also affect the teacher's teaching effect. Students are difficult to grasp the teaching of the balance between the objective conditions and the subjective desire [8].

Improve the teaching quality of higher vocational college education, the key is rapidly promote the teachers' professional ability, the construction of national demonstrative higher vocational colleges by provides the reference for the development of the higher vocational teachers' professional ability, the author from the government, schools and the teachers' three aspects to explore the effective ways to improve the ability of higher vocational college teachers' professional set. (1) Leadership should understand the needs of teachers in the higher vocational colleges, establishing incentive mechanism, improve the teachers' work enthusiasm, to promote the teachers' self-learning, self-assessment and the reflection ability, such as to teachers in-depth field research, skills training subsidies, to get skill level certificate of teachers shall be rewarded. (2) National specification should be in the form of system established scientific standard of higher vocational college teachers' professional ability, indicate the direction to the school and the teacher, only the direction is clear, hard to be meaningful, at the same time should be adjusted the higher vocational college teachers' occupational qualification certification system. (3) Teachers should firm belief education in higher vocational colleges, fully understand the importance of professional career value feeling, love education career, love the students, only with the firm belief of education, in order to make a commitment to work that not afraid of difficulties and the challenges, in the general event of a timely adjust their job burnout.
The Modified Education Mode. Under the multicultural background, protect and carry forward the national and local culture is a hot spot of contemporary cultural study and cultural education, it is not only beneficial to protect the diversity of cultural ecology, but also to protect the inherent value of national and local culture, make people of different ethnic and regional spiritual identity, self-esteem and self-confidence. Save and carry forward the national and local culture, however, we can't just be in the form of books, also should not only use images, video and sound recording, must will exist in a state of activation in everyone's heart, will have vitality. Education as the spirit of a nation, cultural heritage tools that is the most inspiring and influence, as a result, the fine arts curriculum and local cultural resources development and utilization of the research is very important practical significance. Under this background, we revise the education mode from the listed perspectives.

$\circ$ The real purpose of education is according to the inherent requirement of individual life, play the potential of the people, found that the value of the guide to perfect the establishment and development of human nature. Art development needs powerful artistic education, so to set up the correct slant with the in-depth understanding of the nature of artistic and cultural behavior.

- Art education workers should pay attention to cultivate wide range of interests, strengthen their innovation consciousness. In addition, should also pay attention to update ideas and the teaching methods, advancing with the times, to achieve the dialectical unification of old and new. At the same time, to encourage students to more personalized development, help them to get hands-on experience by autonomous learning activities. 
- The teacher is the leader of the teaching link and commanders, bear the mission of cultivating students' innovative ability. Traditional books may have a time lag of teaching content that students may not be able to generate interest in learning. At this time, the teacher can choose according to the need of teaching to better complete teaching mission of the teaching content, and adopt flexible teaching means to strengthen students' innovation ability.

National culture to infiltrate the sketch, color, design basis for fine arts courses, life with its rich heritage, rich resources of art creation as on this basis, and establishes the backbone teachers training rooms for academic leader campus with off-campus practice base. Direct students to learn the rising enthusiasm, art design and creation, to form the teachers in the fine arts creation, research brings along the changes of art teaching ideas and teaching methods, students in the fine arts creation stimulating the enthusiasm of the learning and creation, to develop the autonomous learning and explore the good atmosphere of learning. To extend the fine arts curriculum resources into the local culture, and rich regional culture not only for the creation of the art design student provides rich design resources, at the same time to make the students in the curriculum practice promoted aesthetic accomplishment, the humanities, inspired the patriotic enthusiasm and the initiative learning interest, gradually formed an active search for knowledge, attach importance to practical ability of active study way, and a positive attitude towards life, and promote their all-round development. Let the students in the process of the learning society life and creation, this is the modern education to the pursuit of goals.

\section{Conclusion}

In this paper, we conduct research on Nantong craft arts resources and corresponding applications on the local higher vocational teaching. With quickening of our country market economy development, the demand for all kinds of the talents not only increased in number, and on the quality of the talent demand is higher and higher, especially complex has certain skills particularly talent market. All these led to update and change of concept of education in our country, and as a practical training, talents of the higher vocational art education in our country, the more active to adapt to changes in the modern social development, as market demand, truly from the aspects of the development of the society, the demand of the market, such as to determine the training objectives of higher vocational art education and students' ability level, as well as for professional localization of higher vocational art education in our country, and on this basis to adjust and reform in vocational art original teaching method, teaching content and teaching mode, in order to realize higher vocational art education in our country and the social actual demand. Correspondingly, our research provides the paradigm for related modification that holds special significance.

\section{References}

[1] Zheng, L. I. "The Micro-course Design for Vocational Skills Teaching Based on the Schema Theory — A Case Study of Tour Guide Major of Higher Vocational Education." Vocational and Technical Education 23 (2014): 008.

[2] Long, J. I. A. N. G. "Analysis of Teaching Mode of College English in Higher Vocational Education." Overseas English 15 (2013): 024.

[3] Yue, C. O. N. G. "Necessity of Sustainable Enhancement of Practical Spoken English Teaching in Higher Vocational Colleges." Journal of Jiangsu Vocational and Technical Institute of Economics and Commerce 2 (2013): 029. 
[4] Peng, H. A. N. "Research of The Combination of Production and Education In Higher Vocational Education In The Period of Economic Transition." (2015).

[5] Ran, Z. H. A. N. G. "Typical Case Analysis of Action Oriented Teaching for the Specialty of Numerical Control Technology in Higher Vocational Education." Industrial Technology and Vocational Education 1 (2013): 009.

[6] Chun-qing, L. I. "Project-based Practice Teaching in Higher Vocational Colleges
[J]." Journal of Yunyang Teachers College 2 (2013): 033.

[7] XU, Zhihua, et al. "Exploration and Practice of Integration of Double Attribute of Mechanical Basic Courses in Aviation Vocational Colleges." Journal of Chengdu Aeronautic Polytechnic 1 (2015): 008.

[8] WU, Heng-yu, and Li-sha CAI. "Exploration and Practice of the Teaching Reform for Digital Electronic Technique Course [J]." Journal of Liaoning Higher Vocational 4 (2013). 